\title{
Electrocardiogram Time
}

National Cancer Institute

\section{Source}

National Cancer Institute. Electrocardiogram Time. NCI Thesaurus. Code C83151.

The time at which the electrocardiogram assessment took place. 